\title{
Interstitial 9q22.3 microdeletion: clinical and molecular characterisation of a newly recognised overgrowth syndrome
}

\author{
Richard Redon $^{1,3}$, Geneviève Baujat ${ }^{2,3}$, Damien Sanlaville ${ }^{2}$, Martine Le Merrer², \\ Michel Vekemans ${ }^{2}$, Arnold Munnich ${ }^{2}$, Nigel P Carter ${ }^{1}$, Valérie Cormier-Daire ${ }^{2}$ and \\ Laurence Colleaux ${ }^{*, 2}$
}

\author{
${ }^{1}$ The Wellcome Trust Sanger Institute, Wellcome Trust Genome Campus, Hinxton, Cambridge, UK; ${ }^{2}$ INSERM U781 \\ and Département de Génétique, Hôpital Necker-Enfants Malades, rue de Sèvres, Paris, France
}

In the course of a systematic whole genome screening of patients with unexplained overgrowth syndrome by microarray-based comparative genomic hybridisation (array-CGH), we have identified two children with nearly identical $6.5 \mathrm{Mb}$-long de novo interstitial deletions at 9q22.32-q22.33. The clinical phenotype includes macrocephaly, overgrowth and trigonocephaly. In addition, both children present with psychomotor delay, hyperactivity and distinctive facial features. Further analysis with a high-resolution custom microarray covering the whole breakpoint intervals with fosmids mapped the deletion breakpoints within 100-kb intervals: although the deletion boundaries are different for the two patients, nearly the same genes are deleted in both cases. We suggest therefore that microdeletion of 9q22.32-q22.33 is a novel cause of overgrowth and mental retardation. Its association with distinctive facial features should help in recognising this novel phenotype.

European Journal of Human Genetics (2006) 14, 759-767. doi:10.1038/sj.ejhg.5201613; published online 29 March 2006

Keywords: overgrowth; mental retardation; chromosomal anomaly; 9q22.3 deletion

\section{Introduction}

Overgrowth syndromes are characterised by the association of increased weight, length or head circumference with a variable combination of macrocephaly, mental retardation, facial dysmorphic features, advanced bone age and hemihyperplasia. The genetic basis for many of these conditions is being increasingly elucidated. Recently, the Sotos syndrome (MIM 117550) - a well-defined condition characterised by pre- and postnatal overgrowth, macrocephaly, developmental delay, advanced bone age and a

*Correspondence: Dr L Colleaux, INSERM U781, Hôpital Necker - Enfants Malades, Tour Lavoisier, 149 rue de Sèvres, 75015 Paris, France.

Tel: + 331444951 60; Fax: + 331473485 14;

E-mail: colleaux@necker.fr

${ }^{3}$ These authors equally contributed to the work

Received 25 October 2005; revised 9 February 2006; accepted 10 February 2006; published online 29 March 2006 typical facial gestalt - has been associated with the presence of point mutations or deletions inactivating the NSD1 gene at 5q35. ${ }^{1,2}$ Similarly, the deregulation of imprinted growth-regulatory genes within the $11 \mathrm{p} 15$ region was identified as the major cause of BeckwithWiedemann syndrome, ${ }^{3}$ a distinct overgrowth condition characterised by macroglossia, abdominal-wall defects, visceromegaly, embryonic tumours, hemihyperplasia, ear anomalies, renal anomalies and neonatal hypoglycaemia (MIM 130850). However, despite these recent advances, the pathogenesis of many overgrowth syndromes remains poorly understood.

Interestingly, several chromosomal duplications and deletions, such as $\operatorname{dup}(4)(\mathrm{p} 16.3)$ and $\operatorname{del}(22)(\mathrm{q} 13)$, have also been associated with overgrowth, ${ }^{4,5}$ indicating that some still unclassified overgrowth syndromes may be caused by subtle genomic imbalanced rearrangements. 

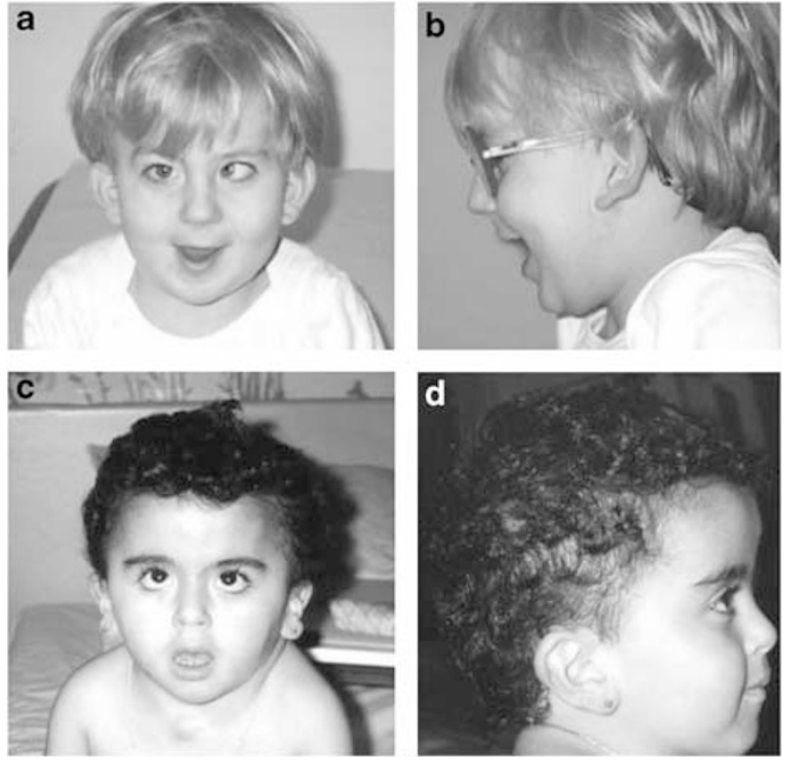

Figure 1 Photographs of patients 1 at age 5 years $(\mathbf{a}, \mathbf{b})$ and patient 2 at age 3 years $(\mathbf{c}, \mathbf{d})$. Note the macrocephaly and the trigonocephaly. Written consents to publish these photographs were obtained from the parents of each child.

In the late 1990s, microarray-based genomic comparative hybridisation (array-CGH) was developed for genome screening of DNA copy number changes. ${ }^{6,7}$ This technique, applied to cohorts of patients with learning disability and associated dysmorphic features, ${ }^{8,9}$ enabled the identification of subtle chromosomal microdeletions and microduplications, which had remained undetected using previous standard screening methods such as karyotyping based on banding patterns.

However, no recurrent deletion or duplication affecting one particular locus has been identified in two preliminary studies, ${ }^{8,9}$ making the association of any specific clinical phenotype with each of these rearrangements difficult to interpret. In contrast, in this report, we describe two unrelated patients presenting with very similar phenotypes - including overgrowth and psychomotor delay - and with nearly identical de novo microdeletions at 9q22.32-q22.33.

\section{Methods \\ Patients}

Case 1 is the first child of unrelated healthy parents of normal stature (father height $176 \mathrm{~cm}$ and mother height $155 \mathrm{~cm}$ ). At birth, the father was 29 and the mother 28 years old. This boy was born after an uncomplicated pregnancy and an uneventful delivery. Birth parameters showed macrosomia with weight at $4540 \mathrm{~g}$ ( $>97$ th percentile), length $55 \mathrm{~cm}$ ( $>97$ th percentile) and occipitofrontal head circumference (OFC) $39 \mathrm{~cm}$ ( $>97$ th percentile). The neonatal period was compromised by hypotonia and sucking difficulties. A sagittal and metopic craniosynostosis led to surgical correction at 6 month of age. Dysmorphic features included trigonocephaly, epicanthic folds, small mouth with thin upper lip, ear pits, low set ears with ear lobule uplift (Figure 1). Other features were noted, including short neck, pectus excavatum, umbilical hernia, strabismus and hyperlaxity. No organomegaly was noticed. Brain MRI, cardiac and renal ultrasound scan and ophtalmological examination were normal. Postnatal overgrowth was also confirmed: at 2 years of age, height was $95 \mathrm{~cm}$ (+3DS), weight $16 \mathrm{~kg}$ (+3DS), OFC $52 \mathrm{~cm}(+3 \mathrm{D})$. Bone age was normal at 2 years. He had severe learning difficulties, and presented behavioural difficulties with hyperactivity. He began to walk unaided at 24 months of age, and could sign a few words at 5 years of age, requiring special education. To date, at 5 years, height was $118 \mathrm{~cm}$ (+2.5DS), weight $24 \mathrm{~kg}$ (+2.5 DS) and OFC $54 \mathrm{~cm}(+2 \mathrm{DS})$ (Figure 2a) The last physical examination did not noticed either skin or other abnormalities.

Case 2 is the first and only girl of healthy nonconsanguineous parents of normal stature (father $170 \mathrm{~cm}$ and mother $165 \mathrm{~cm}$ ). At birth, mother was 41 and father was 31 years old. After a term pregnancy and normal delivery, she was born with overgrowth: birthweight was $5070 \mathrm{~g}$ (>97 percentile), length $53 \mathrm{~cm}$ ( $>97$ percentile) and OFC $41 \mathrm{~cm}$ (>97 percentile). The neonatal period was complicated by feeding difficulties and hypotonia, and because of a sternal abcess, was discovered with a thyroglossal cyst with sternal fistula. At that time, renal and cervical ultrasonograms were normal, head ultrasonogram showed large ventricles and skeletal survey revealed advanced bone age $(+2$ years of bone age). She was referred to the genetic clinic at the age of 10 months. On clinical

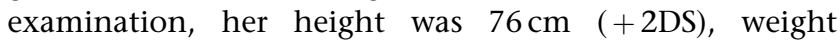

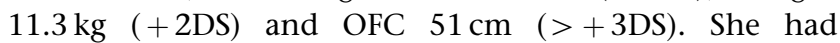
trigonocephaly and some dysmorphic features with epicanthic folds, downslanting palpebral fissures, a small mouth with a thin upper lip, thickened ears with ear lobule indentation (Figure 1). There were pectus excavatum, short neck, umbilical hernia, bilateral medium palmar crease and strabismus. Milestones were delayed. Brain MRI showed ventriculomegaly by atrophy, a thin corpus callosum and no structural abnormalities. At 33 months of age, her height was $98 \mathrm{~cm}(+2 \mathrm{DS})$, weight $16 \mathrm{~kg}$ (+3DS) and OFC $54.5 \mathrm{~cm}(+4 \mathrm{DS})$, and one pimented nevi on shoulder area was identified. During the following years, her height and weight continued at $+2 \mathrm{DS}$ and the OFC far above $+3 \mathrm{DS}$ (Figure 2b). The developmental delay was severe with no independent walking at 8 years and only a few words at that time. Behavioural problems included hyperactivity. In addition, the patient developed a seizure disorder at 3 years of age and had since been on treatment with sodium valproate with good effect. At 8 years, a dorsal cyphosis was discovered. Dentition was also delayed, with no definitive teeth at 8 years. 

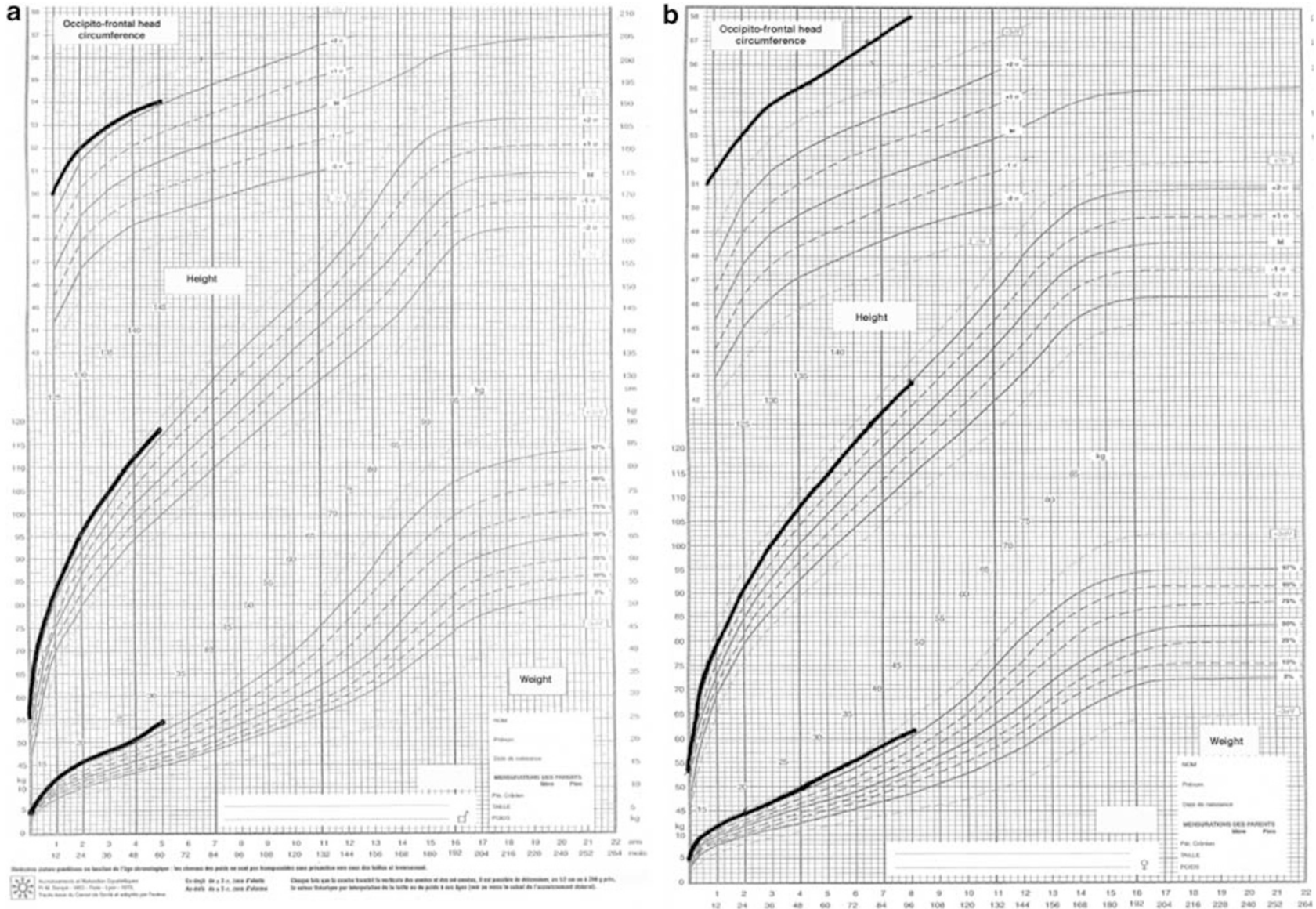

Figure 2 Growth charts of our patients. (a) For case 1 and (b) for case 2.

In both cases, high-resolution banding of peripheral blood lymphocytes showed normal karyotypes with no evidence of deletions or duplications.

Table 1 summarises the clinical features observed in both patients.

\section{Chromosome and fluorescent in situ hybridisation (FISH) analyses}

Metaphase spreads were prepared from phytohaemaglutinin-stimulated peripheral blood lymphocyte cultures using standard procedures of hypotonic treatment and methanol/acetic acid fixation (3:1). RHG- and GTG-banding analyses were performed according to standard protocols. FISH for clone verification was conducted following conventional methods using metaphase chromosomes prepared from a karyotypically normal male lymphoblastoid cell line. Degenerate oligonucleotide primer (DOP) amplified clone DNA (used in array production) was labelled with biotin-16-dUTP (Roche, Mannheim, Germany) or digoxigenin-11-dUTP (Roche) by nick translation. Biotin-labelled probes were detected using Avidin
TexasRed (Molecular Probes, Eugene, OR, USA), while digoxin-labelled probes were detected with a combination of mouse antidigoxigenin (Vector Laboratories, Peterborough, UK) and goat anti-mouse FITC (Sigma-Aldrich, Dorset, UK) antibodies.

\section{Molecular analyses}

Blood samples from probands and their parents were obtained after informed consent and genomic DNA was isolated from EDTA anticoagulated blood by a salting out procedure. Fluorescent genotyping was performed as previously described. ${ }^{10}$

\section{Array-CGH}

The $1 \mathrm{Mb}$ resolution arrays used in this study are as described previously. ${ }^{11}$ The clone set used for the construction of these arrays was verified by end sequencing and is available from the Sanger Institute. Fosmid clones were selected using the FosEndPairs mapping data set available at http://genome.ucsc.edu, in order to cover at tiling path resolution the two $2-\mathrm{Mb}$ intervals containing the proximal 
Table 1 Clinical manifestations in the two patients carrying the deletion at $9 q 22.32-q 22.33$

\begin{tabular}{|c|c|c|}
\hline Clinical features & Case 1 & Case 2 \\
\hline $\begin{array}{c}\text { Birth parameters } \\
\text { Height }(\mathrm{cm}) \\
\text { Weight }(\mathrm{g}) \\
\text { OFC }(\mathrm{cm})\end{array}$ & $\begin{array}{l}\text { Macrosomy } \\
55 \\
4540 \\
39\end{array}$ & $\begin{array}{l}\text { Macrosomy } \\
53 \\
5070 \\
41\end{array}$ \\
\hline Neonatal period & $\begin{array}{l}\text { Hypotonia } \\
\text { Feeding difficulties }\end{array}$ & $\begin{array}{l}\text { Hypotonia } \\
\text { Feeding difficulties }\end{array}$ \\
\hline Craniofacial features & $\begin{array}{l}\text { Trigonocephaly } \\
\text { Epicanthic folds } \\
\text { Small mouth } \\
\text { Thin upper lip } \\
\text { Low set ears } \\
\text { Ear lobule uplift } \\
\text { Ear pits }\end{array}$ & $\begin{array}{l}\text { Downslanting palpebral fissures } \\
\text { Trigonocephaly } \\
\text { Epicanthic folds } \\
\text { Small mouth } \\
\text { Thin upper lip } \\
\text { Low set ears } \\
\text { Ear lobule uplift } \\
\text { Ear lobe thickened }\end{array}$ \\
\hline Others congenital features & $\begin{array}{l}\text { Short neck } \\
\text { Pectus excavatum } \\
\text { Strabismus } \\
\text { Umbilical hernia } \\
\text { Hyperlaxity }\end{array}$ & $\begin{array}{l}\text { Short neck } \\
\text { Pectus excavatum } \\
\text { Strabismus } \\
\text { Umbilical hernia } \\
\text { Median palmar crease } \\
\text { Thyroglossal cyst }\end{array}$ \\
\hline Psychomotor and behavioural development & $\begin{array}{l}\text { Major global delay } \\
\text { Hyperactivity }\end{array}$ & $\begin{array}{l}\text { Major global delay } \\
\text { Hyperactivity }\end{array}$ \\
\hline $\begin{array}{l}\text { Neurology } \\
\text { Dermatology }\end{array}$ & & $\begin{array}{l}\text { Seizures } \\
1 \text { café au lait spot }\end{array}$ \\
\hline
\end{tabular}

and distal deletion breakpoints. Twenty-six fosmids corresponding to chromosome 18 sequences were added to the selection and used as control clones for normalisation. All fosmid clones are available at the Wellcome Trust Sanger Institute (http://www.sanger.ac.uk/cgi-bin/teams/team38/ CloneRequest/CloneRequest). After fosmid DNA extraction, DOP-PCR and amino-linked PCR products were generated, arrayed in duplicate onto amine-binding slides (CodeLink $^{\mathrm{TM}}$ Activated Slides, Amersham Biosciences) and hybridised as previously described. ${ }^{11}$ Array-CGH was undertaken generally as described. ${ }^{9,11}$

\section{Image and data analysis}

Large insert clone $1-\mathrm{Mb}$ microarrays were analysed as previously described. ${ }^{9}$ Fosmid microarrays were scanned using an Agilent scanner (Agilent Technologies). Fluorescent intensities were extracted using GenePix Pro 5.0 software (Axon Instruments). Spots were defined by use of the automatic grid feature of the software and manually adjusted where necessary. Spots with fluorescence intensities lower than twice the local background value were excluded from analysis. Fluorescence intensities of all spots were then corrected by subtraction of the local background value. Mean values for each duplicate spot were obtained. Clones were excluded whenever the individual values obtained for the duplicates differed from each other by more that $15 \%$. Clones were mapped using the NCBI Build 35 of the human genome sequence, according to end sequencing data. Data were normalised by dividing the ratio of each clone by the mean ratio of the 26 clones mapped on chromosome 18 . We considered a region to be deleted where the hybridisation ratio of corresponding clones was lower than -4 SD.

The two cases described in this report have been submitted to the DECIPHER database (http://decipher. sanger.ac.uk) providing access to detailed phenotype information and viewing of the genomic imbalances within the context of the genome browser, Ensembl (http://www.ensembl.org/Homo_sapiens/index.html).

\section{Results}

We have recently published the screening of microdeletions and microduplications in 50 patients with learning disability and dysmorphic features using array-CGH at $1-\mathrm{Mb}$ resolution. ${ }^{9}$ This analysis allowed us to identify one patient presenting with mental retardation and overgrowth, and carrying a deletion involving 11 clones at 9q22.32-q22.33 (patient 1 in the present report, Figure $3 \mathrm{a})$. The size of the deleted segment is less than 

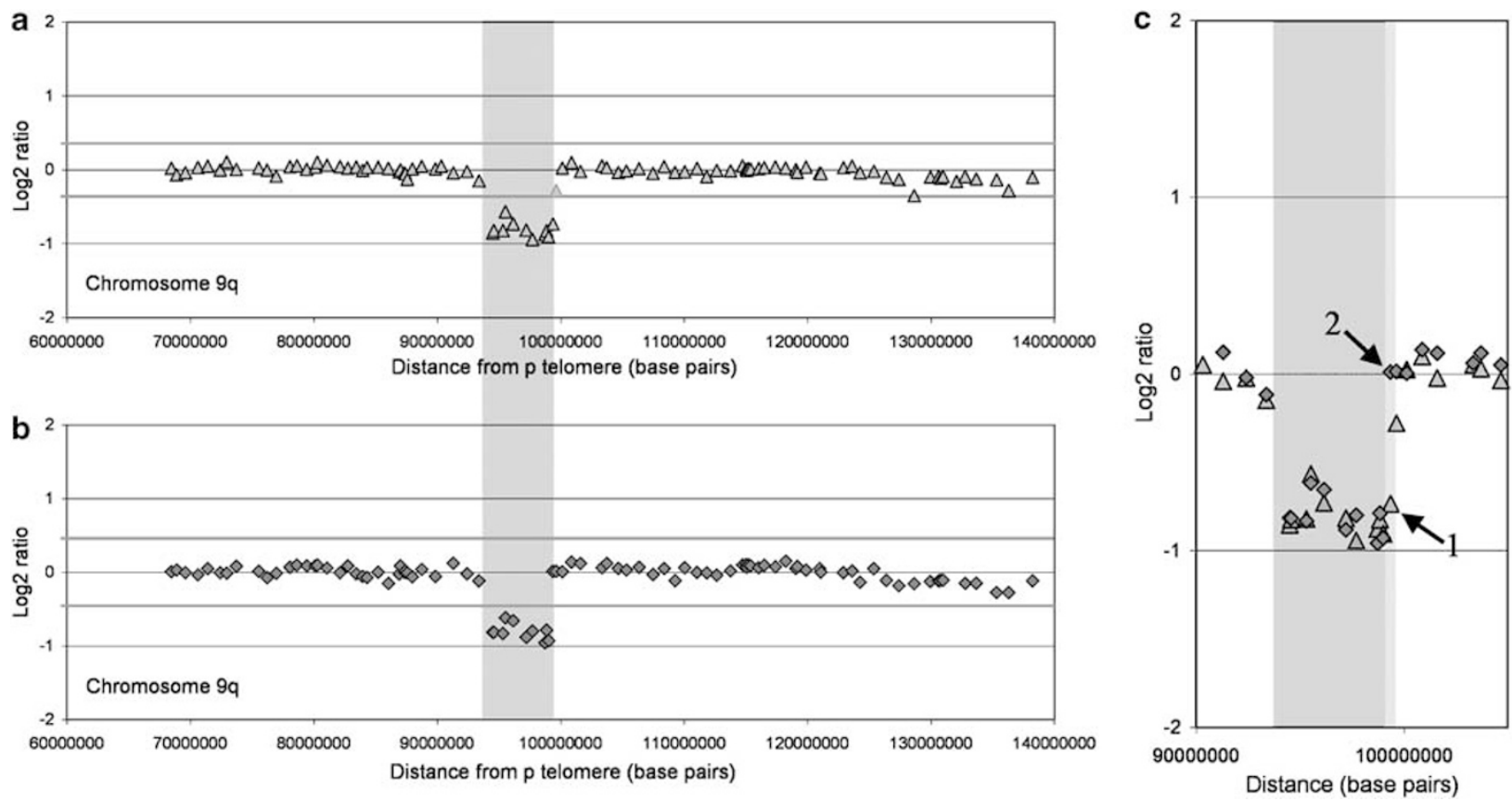

Figure 3 Chromosome $9 q 22.3$ deletions in two patients with unclassified overgrowth syndrome. (a, b) Chromosome $9 q$ array-CGH ratio profiles identifying very similar deletions restricted to $9 q 22.3$ for patients 1 (a) and 2 (b). The $X$-axis represents the distance in base pairs along the chromosome from the $p$ telomere. The $Y$-axis represents the hybridisation ratio plotted on a log 2 scale. Grey lines indicate thresholds for clone deletion or duplication (array ratio mean $\pm 4 \mathrm{SD}$ ), the grey box the common deleted segment at $9 \mathrm{q} 22.3$. (c) Detailed comparison of the array-CGH profiles indicating deletions at $9 \mathrm{q} 22.3$ for patients 1 and 2 . The proximal breakpoint intervals appear identical for both patients at this resolution. In contrast, the distal breakpoints are distinct: the BAC clone RP11-547C13 gives a decreased ratio indicating deletion only for patient 1 (black arrow 1 ), while its ratio is unaffected for patient 2 (black arrow 2).

Table 2 Deletion mapping at 9q22.3 using the large insert clone $1 \mathrm{Mb}$ microarray

\begin{tabular}{|c|c|c|c|c|c|}
\hline Clone name & Chromosome & Start & End & Patient 1 & Patient 2 \\
\hline RP11-19J3 & 9 & 92321634 & 92489352 & -0.02 & -0.02 \\
\hline RP11-30L4 & 9 & 93288305 & 93459139 & -0.15 & -0.12 \\
\hline RP11-333I7 & 9 & 94415600 & 94590889 & -0.85 & -0.81 \\
\hline RP11-279I21 & 9 & 94473904 & 94655715 & -0.82 & -0.82 \\
\hline RP11-43505 & 9 & 95213051 & 95402627 & -0.82 & -0.83 \\
\hline RP11-160D19 & 9 & 95433765 & 95598231 & -0.57 & -0.62 \\
\hline RP11-240L7 & 9 & 96060259 & 96229878 & -0.73 & -0.65 \\
\hline RP11-23J9 & 9 & 97120587 & 97286003 & -0.82 & -0.88 \\
\hline RP11-23B15 & 9 & 97623563 & 97784334 & -0.94 & -0.80 \\
\hline RP11-92C4 & 9 & 98644256 & 98794171 & -0.88 & -0.96 \\
\hline RP11-192E23 & 9 & 98744783 & 98745226 & -0.82 & -0.79 \\
\hline RP11-96L7 & 9 & 98922778 & 99098674 & -0.90 & -0.93 \\
\hline RP11-547C13 & 9 & 99270898 & 99449952 & -0.73 & 0.01 \\
\hline RP11-463M14 & 9 & 99548194 & 99709828 & -0.28 & 0.01 \\
\hline RP11-208F1 & 9 & 100050139 & 100197864 & 0.02 & 0.01 \\
\hline
\end{tabular}

Bold characters indicate clones found deleted by array. CGH analysis.

$6.5 \mathrm{Mb}$ in length, between clones RP11-30L4 and RP11463M14 (Table 2).

This result was further confirmed by the irregular inheritance of polymorphic microsatellite markers with a single maternal contribution and no paternal contribution at this locus (Table 3) while other chromosomes showed regular bi-parental inheritance (data not shown). Finally, FISH analyses using a probe specific of chromosome $9 q 22$ on metaphase nuclei from blood lymphocytes from proband and parents confirmed our finding and showed that the deletion occurred de novo (not shown).

Clinical and dysmorphic similarities with patient 1 prompted us to test for $9 q 22$ anomalies in patient 2 . Array-CGH, genotyping and FISH analyses revealed that the child carried a similar deletion (about $6 \mathrm{Mb}$ in length) at 9q22.3 (Figure 3b). The rearrangement was 
Table 3 Genotype analysis using chromosome 9 markers confirms the $9 q 22.3$ deletions and demonstrates the paternal origin of the deletion

\begin{tabular}{lccccrr}
\hline Locus $^{\mathrm{a}}$ & Position $(\mathrm{Mb})$ & Father & $\begin{array}{c}\text { Patient } 1 \\
\text { Child }\end{array}$ & Mother & Father & $\begin{array}{c}\text { Patient 2 } \\
\text { Child }\end{array}$ \\
\hline D9S1815 & 89.7 & $223 / 225$ & $223 / 225$ & $223 / 233$ & ND & $225 / 227$ \\
D9S287 & 93.8 & 268 & 270 & $268 / 270$ & $168 / 170$ & ND \\
D9S1809 & 93.9 & $124 / 138$ & 122 & $122 / 124$ & 122 & 172 \\
D9S1851 & 94.9 & $144 / 148$ & 148 & $142 / 148$ & $142 / 146$ & 122 \\
D9S1690 & 99.4 & $223 / 225$ & $223 / 225$ & $223 / 233$ & ND & $122 / 132$ \\
\hline
\end{tabular}

a Loci are listed according to their relative chromosomal position from pter to qter. Allele sizes are given in base pairs. ND: not determined.

Bold characters indicate genotype which are consistent with a paternal deletion.

found to be de novo and of paternal origin in this case as well (Table 3).

Both patients appeared to have very similar molecular anomalies. Indeed, at a $1-\mathrm{Mb}$ resolution, the proximal deletion breakpoints appear identical while the distal breakpoints differ by only one clone. To refine the mapping of the breakpoints, we generated a microarray that included a set of fosmid clones covering the $2 \mathrm{Mb}$ regions encompassing the proximal and distal breakpoints (Figure 3c and Table 4). Comparative hybridisation using these arrays allowed us to restrict each deletion boundary to an interval smaller than $100 \mathrm{~kb}$.

For patient 1, the proximal breakpoint was mapped within the chromosome interval 93,372,715$93,438,558 \mathrm{Mb}$ while the distal breakpoint was mapped within 99,648,482-99,728,513 Mb (Figure 4). For patient 2, the proximal breakpoint was mapped within 93,399,533$93,482,253 \mathrm{Mb}$ and the distal breakpoint within $99,142,876-99,210,789 \mathrm{Mb}$. These results indicate that 56 predicted Ensembl genes are deleted in both patients 1 and 2. Four additional Ensembl genes could be affected either in one or both patients.

A second, small genomic segment was found deleted in patient 2, with breakpoints located within 93,107,684$93,178,697 \mathrm{Mb}$ and $93,204,833-93,275,711 \mathrm{Mb}$. One single gene could be disrupted at this locus (ENSG00000165238; WNK2). This second small deletion was confirmed by CGH with high-resolution microarrays composed of genomic small-insert clones (data not shown). It was present neither in paternal nor in maternal DNA (not shown).

\section{Discussion}

We report here two unrelated cases with de novo 9q22.32q22.33 microdeletions. More than fifteen patients with cytogenetically visible 9q22 deletion have already been reported, ${ }^{12-15}$ but in all cases, the deletion was detected by $G$ banding analysis and encompasses a larger genomic region. Despite the heterogeneity of the size of the deletions, several common features emerge including mental retardation and some cranio-facial features, that is, frontal bossing and epicanthic folds. However, trigono- cephaly, overgrowth and small mouth, which are characteristic findings in the two presented cases, have not been described for imbalance in this region. Moreover, while monosomy at $9 \mathrm{q} 22$ is frequently associated with basal cell nevus syndrome (BCNS, Gorlin-Goltz syndrome, OMIM\# 109400), the two cases reported here do not support this diagnosis. Indeed, apart from the relative macrocephaly, none of the characteristic BCNS features mandibular prognathism, skeletal abnormalities, palmar/ plantar cysts and basal cell carcinoma ${ }^{16-18}$ - were observed. However, because numerous aspects of BCNS have an age-dependent penetrance (the median age of Gorlin onset is 25 years), BCNS may be challenging to diagnose on clinical grounds alone, especially in early childhood. ${ }^{19}$

The array-CGH profiles obtained with the whole genome microarray at $1-\mathrm{Mb}$ resolution suggested that the proximal deletion breakpoint could be identical in both patients while the distal breakpoints were very close, differing by only one clone. Conversely, deletion profiles obtained using the high-resolution fosmid microarray show that (i) at the proximal boundary, breakpoints for patients 1 and 2 are separated by less than $90 \mathrm{~kb}$ (differing by one unique clone); (ii) at the distal deletion boundary, the breakpoint for patient 1 is $440-590 \mathrm{~kb}$ more distal than for patient 2; (iii) a maximum of two genes could be deleted within this additional deleted segment for patient 1, thus explaining the very similar clinical presentations; (iv) a second smaller deletion was detected only for patient 2, proximal to the larger deletion, indicating a greater degree of complexity of the rearrangement for this patient than for patient 1 . Altogether, our results show that the deletions found in the two patients are very similar in terms of gene content and are likely to be responsible for the matched phenotypic features.

The nature of the events leading to the deletions in patients 1 and 2 appear different. While the deletion in patient 1 appears to be a simple loss of one continuous genomic segment, the pattern of deletion observed in patient 2 can only be explained by the occurrence of two independent events: either two independent (simultaneous or consecutive) deletions, or one DNA inversion including the proximal breakpoint followed by one unique 

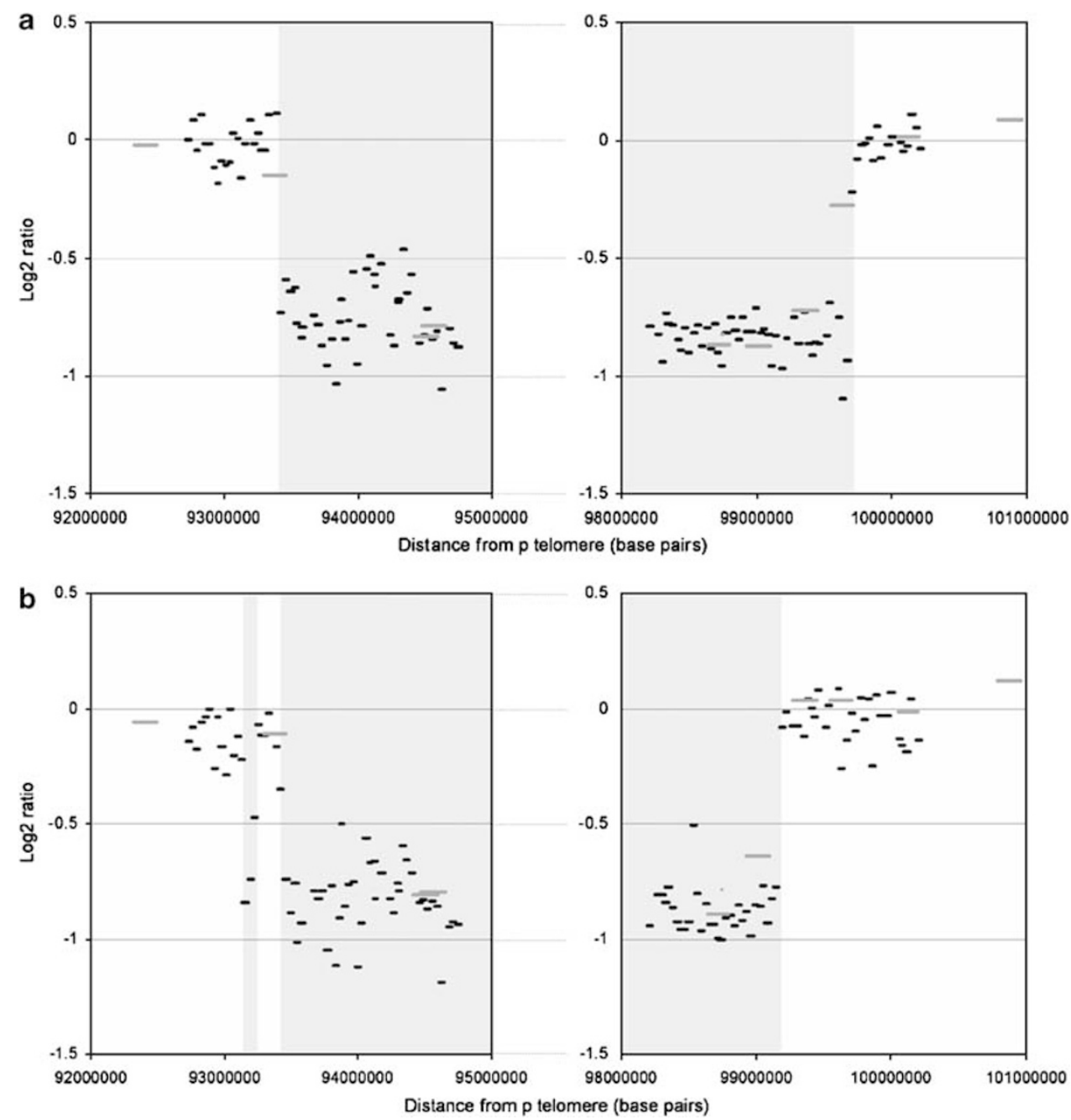

Figure 4 High-resolution mapping of the 9q22.3 deletion breakpoints. Array CGH profiles at the proximal (left) and distal (right) breakpoints for patients 1 (a) and 2 (b). Clones from the $1 \mathrm{Mb}$ whole genome microarray are indicated by large grey bars and clones from the custom tiling path microarray composed of fosmids are indicated by short black bars. The $X$-axis represents the distance in base pairs along chromosome 9 from the $p$ telomere. The $Y$-axis represents the hybridisation ratio plotted on a log2 scale. Grey boxes indicate deleted chromosomal segments.

large deletion. Moreover, as the proximal and the distal breakpoint intervals do not contain any sequence homology for either patient, we postulate that none of these deletions was generated by nonallelic homologous recombination, ${ }^{20}$ but rather that they may have occurred via nonhomologous end joining of DNA breaks. In conclusion, our results illustrate how high-resolution genomic microarrays facilitate the high-resolution delineation of breakpoint regions and provide a strong argument for the more widespread adoption of microarray analysis for systematic characterisation of genome rearrangements associated with human syndromes.

Noticeably, a recent study, aiming to identify genomic regions linked to height through a whole genome scan, showed the highest multipoint LOD score (2.74) on chromosome 9 with the marker D9S287, ${ }^{21}$ which is deleted in both patients in our study. The common region deleted in both patients encompasses 56 Ensembl predicted genes, two of which are of particular interest. The first one encodes the precursor of gamma-aminobutyric acid type $\mathrm{B}$ receptor, subunit 2 (GABA-BR2 also known as GPR51). Metabotropic gamma-aminobutyric acid receptors play modulatory roles in central synaptic transmission and are involved in neuronal migration during development of the central nervous system. ${ }^{22}$ GPR51 haploinsufficiency may therefore play a critical role in the development of mental retardation in these patients. The second gene of interest is type 1 transforming growth factor beta receptor (TGFBR1). TGF-beta signalling has a pivotal role in the regulation of a wide variety of physiological processes from development to pathogenesis and its deregulation been implicated in the pathogenesis of a variety of diseases. It was recently 
Table 4 Deletion mapping at 9q22.3 with the custom fosmid microarray

\begin{tabular}{|c|c|c|c|c|c|}
\hline Clone name & Chromosome & Start & End & Patient 1 & Patient 2 \\
\hline G248P88411D3 & 9 & 93081285 & 93118761 & 0.01 & -0.12 \\
\hline G248P87963F7 & 9 & 93107684 & 93146517 & -0.16 & -0.22 \\
\hline G248P80232D4 & 9 & 93133289 & 93178697 & -0.02 & -0.84 \\
\hline G248P81890C6 & 9 & 93172563 & 93213417 & 0.09 & -0.74 \\
\hline G248P88898F10 & 9 & 93204833 & 93242625 & -0.01 & -0.47 \\
\hline G248P8476A10 & 9 & 93236538 & 93275711 & 0.03 & -0.07 \\
\hline $\mathrm{G} 248 \mathrm{P} 8542 \mathrm{H} 1$ & 9 & 93249556 & 93287782 & -0.05 & -0.11 \\
\hline G248P83994C9 & 9 & 93282808 & 93320752 & -0.04 & -0.11 \\
\hline G248P87879A9 & 9 & 93309396 & 93352684 & 0.11 & -0.02 \\
\hline G248P88896G8 & 9 & 93372715 & 93412619 & 0.11 & -0.17 \\
\hline G248P88925F2 & 9 & 93399533 & 93438558 & -0.73 & -0.35 \\
\hline G248P88221G3 & 9 & 93440790 & 93482253 & -0.59 & -0.74 \\
\hline G248P88447B1 & 9 & 93474837 & 93518973 & -0.64 & -0.89 \\
\hline G248P87522F9 & $\dddot{9}$ & 99123809 & 99161561 & -0.83 & -0.77 \\
\hline G248P80346H9 & 9 & 99142876 & 99180679 & NA & -0.59 \\
\hline G248P85875E8 & 9 & 99171888 & 99210789 & -0.97 & -0.08 \\
\hline G248P81313E10 & 9 & 99204594 & 99241586 & -0.84 & -0.01 \\
\hline G248P84240D6 & 9 & 99236895 & 99280098 & NA & -0.03 \\
\hline G248P8770H5 & 9 & 99255244 & 99297212 & -0.75 & -0.07 \\
\hline G248P8948E11 & 9 & 99289032 & 99332705 & -0.86 & -0.08 \\
\hline G248P81615H4 & 9 & 99305353 & 99344623 & NA & -0.36 \\
\hline G248P82949B10 & 9 & 99336816 & 99377528 & -0.73 & -0.12 \\
\hline G248P88677E11 & 9 & 99367593 & 99407865 & -0.86 & 0.04 \\
\hline G248P86061B10 & 9 & 99392796 & 99429306 & -0.91 & 0.00 \\
\hline G248P800721F9 & 9 & 99410279 & 99447599 & -0.86 & -0.03 \\
\hline G248P81909C11 & 9 & 99440533 & 99479667 & -0.86 & 0.08 \\
\hline G248P87521B11 & 9 & 99495280 & 99535821 & -0.83 & -0.08 \\
\hline G248P84070D8 & 9 & 99515669 & 99556191 & -0.69 & 0.01 \\
\hline G248P87635A1 & 9 & 99563785 & 99601477 & -0.83 & NA \\
\hline G248P8526D12 & 9 & 99591657 & 99628580 & -0.75 & 0.09 \\
\hline G248P86605F10 & 9 & 99618680 & 99656345 & -1.10 & -0.26 \\
\hline G248P80087D6 & 9 & 99648482 & 99693056 & -0.94 & -0.13 \\
\hline G248P83738H12 & 9 & 99686914 & 99728513 & -0.22 & -0.02 \\
\hline G248P87518E3 & 9 & 99719297 & 99761009 & -0.08 & -0.10 \\
\hline
\end{tabular}

Bold characters indicate clones found deleted by array. CGH analysis.

demonstrated that heterozygous loss-of-function mutations in the TGFBR1 gene cause multiple developmental anomalies, the Loeys-Dietz syndrome. ${ }^{23}$ However, cranial and facial features observed in this syndrome are distinct from the one observed in our two cases. In addition, generalised arterial tortuosity, which is a specific feature of Loeys-Dietz syndrome, is not present in these two patients. In vivo experiments are presently ongoing to assess TGF-beta signalling in fibroblasts from the patients to test whether haploinsufficiency of the TGFBR1 gene is associated with a defect in this signalisation pathway.

In conclusion, we have described in this report two unrelated patients presenting with very similar clinical traits including psychomotor delay, overgrowth and recognisable typical facial gestalt and with nearly identical de novo 9q22.32-q22.33 microdeletions. Based on these observations, we propose that 9q22.32-q22.33 microdeletion syndrome is a novel cause of overgrowth and mental retardation. We therefore suggest giving consideration to cryptic deletion of chromosome 9q22 in the diagnosis of unexplained overgrowth/mental retardation syndromes.

\section{Acknowledgements}

We are grateful to the patients and their family for their cooperation. We thank Heike Fiegler, Barbara Gorick, Dimitrios Kalaitzopoulos as well as Oliver Dovey and the microarray facility at the Sanger Institute for their assistance. This study was supported by the Fondation de France and the Wellcome Trust. Richard Redon was supported by a Sanger Institute Postdoctoral Fellowship.

\section{References}

1 Kurotaki N, Imaizumi K, Harada $\mathrm{N}$ et al: Haploinsufficiency of NSD1 causes Sotos syndrome. Nat Genet 2002; 30: 365-366.

2 Douglas J, Hanks S, Temple IK et al: NSD1 mutations are the major cause of Sotos syndrome and occur in some cases of Weaver syndrome but are rare in other overgrowth phenotypes. Am J Hum Genet 2003; 72: 132-143.

$3 \mathrm{Li} \mathrm{M}$, Squire JA, Weksberg R: Molecular genetics of WiedemannBeckwith syndrome. Am J Med Genet 1998; 79: 253-259.

4 Partington MW, Fagan K, Sonbjaki V, Turner C: Translocations involving 4p16.3 in three families: deletion causing the PittRogers-Danks syndrome and duplication resulting in a new overgrowth syndrome. J Med Genet 1997; 34: 719-728.

5 Fujita Y, Mochizuki D, Mori Y et al: Girl with accelerated growth, hearing loss, inner ear anomalies, delayed myelination of the brain, and del(22) (q13.1q13.2). Am J Med Genet 2000; 92: 195-199. 
6 Solinas-Toldo S, Lampel S, Stilgenbauer S et al: Matrix-based comparative genomic hybridization: biochips to screen for genomic imbalances. Genes Chromosomes Cancer 1997; 20: 399-407.

7 Pinkel D, Segraves R, Sudar D et al: High resolution analysis of DNA copy number variation using comparative genomic hybridization to microarrays. Nat Genet 1998; 20: 207-211.

8 Vissers LE, de Vries BB, Osoegawa K et al: Array-based comparative genomic hybridization for the genomewide detection of submicroscopic chromosomal abnormalities. Am J Hum Genet 2003; 73: $1261-1270$.

9 Shaw-Smith C, Redon R, Rickman L et al: Microarray based comparative genomic hybridisation (array-CGH) detects submicroscopic chromosomal deletions and duplications in patients with learning disability/mental retardation and dysmorphic features. J Med Genet 2004; 41: 241-248.

10 Colleaux L, Rio M, Heuertz S et al: A novel automated strategy for screening cryptic telomeric rearrangements in children with idiopathic mental retardation. Eur J Hum Genet 2001; 9: 319-327.

11 Fiegler $\mathrm{H}$, Carr P, Douglas EJ et al: DNA microarrays for comparative genomic hybridization based on DOP-PCR amplification of BAC and PAC clones. Genes Chromosomes Cancer 2003; 36: $361-374$.

12 Boonen SE, Stahl D, Kreiborg S et al: Delineation of an interstitial $9 \mathrm{q} 22$ deletion in basal cell nevus syndrome. Am J Med Genet A 2005; 30: 324-328.

13 Olivieri C, Maraschio P, Caselli D et al: Interstitial deletion of chromosome 9, int del(9)(9q22.31-q31.2), including the genes causing multiple basal cell nevus syndrome and Robinow/ brachydactyly 1 syndrome. Eur J Pediatr 2003; 162: 100-103.
14 Shimkets R, Gailani MR, Siu VM et al: Molecular analysis of chromosome 9q deletions in two Gorlin syndrome patients. Am J Hum Genet 1996; 59: 417-422.

15 Sasaki K, Yoshimoto T, Nakao $\mathrm{T}$ et al: A nevoid basal cell carcinoma syndrome with chromosomal aberration. No To Hattatsu 2000; 32: 49-55.

16 Gorlin RJ, Goltz RW: Multiple nevoid basal-cell epithelioma, jaw cysts and bifid rib. A syndrome. N Engl J Med 1960; 262: 908-912.

17 Evans DG, Ladusans EJ, Rimmer S et al: Complications of the naevoid basal cell carcinoma syndrome: results of a population based study. J Med Genet 1993; 30: 460-464.

18 Kimonis VE, Goldstein AM, Pastakia B et al: Clinical manifestations in 105 persons with nevoid basal cell carcinoma syndrome. Am J Med Genet 1997; 69: 299-308.

19 Cowan R, Hoban P, Kelsey A et al: The gene for the naevoid basal cell carcinoma syndrome acts as a tumour-suppressor gene in medulloblastoma. Br J Cancer 1997; 76: 141-145.

20 Inoue K, Lupski JR: Molecular mechanisms for genomic disorders. Annu Rev Genomics Hum Genet 2002; 3: 199-242.

$21 \mathrm{Liu}$ YZ, Xu FH, Shen $\mathrm{H}$ et al: Genetic dissection of human stature in a large sample of multiplex pedigrees. Ann Hum Genet. 2004; 68: $472-488$.

22 Jones KA, Borowsky B, Tamm JA et al: GABA(B) receptors function as a heteromeric assembly of the subunits GABA(B)R1 and GABA(B)R2. Nature 1998; 396: 674-679.

23 Loeys BL, Chen J, Neptune ER et al: A syndrome of altered cardiovascular, craniofacial, neurocognitive and skeletal development caused by mutations in TGFBR1 or TGFBR2. Nat Genet 2005; 37: 275-281. 